\title{
Evaluation of Compatibility and Stability of Filtered 99mTc-Sulfur Colloid When Combined with Fluorescent Indocyanine Green Dye
}

\author{
Karissa M. Hegseth, Amy M. Warren, Joseph C. Hung, and Elton A. Mosman \\ Division of Nuclear Medicine, Mayo Clinic, Rochester, Minnesota
}

\begin{abstract}
It is a common practice to administer dyes and radiopharmaceuticals separately for the localization of sentinel nodes in patients with biliary tract malignancies. The objective of this study was to evaluate the chemical properties and particle size of filtered $99 \mathrm{mTc}$-sulfur colloid before and after it is combined with indocyanine green for injection. This study also evaluated the compatibility and stability of the two when combined, for the possibility of a single injection. Methods: ${ }^{99 m T c-s u l f u r ~ c o l l o i d ~ w a s ~}$ prepared according to the package insert, and the final preparation was passed through a sterile $0.2-\mu \mathrm{m}$ filter. Green dye was also prepared as per the package insert. In a sterile syringe, $0.25 \mathrm{~mL}$ of $14.8-\mathrm{MBq}(400-\mu \mathrm{Ci})$ filtered $99 \mathrm{mTc}$-sulfur colloid was mixed with $0.25 \mathrm{~mL}$ of $1.25-\mathrm{mg}$ green dye in a $1: 1$ proportion for a total volume of $0.50 \mathrm{~mL}$. The radiochemical purity and $\mathrm{pH}$ of filtered $99 \mathrm{mTc}$-sulfur colloid were obtained immediately and at 1 and $2 \mathrm{~h}$ after preparation. Particle size was analyzed using an electron microscope immediately and at $2 \mathrm{~h}$. Results: The average radiochemical purity was $97.6 \% \pm 2.0 \%(n=51)$. The average $\mathrm{pH}$ was $5.56 \pm 0.26(n=51)$. Evaluation of the particle size of filtered $99 \mathrm{mT}$ c-sulfur colloid with the green dye was determined by electron microscopy to be an average of $53 \pm 30 \mathrm{~nm}(n=365)$ at $0 \mathrm{~h}$ and $60 \pm 35 \mathrm{~nm}(n=303)$ at $2 \mathrm{~h}$. This was compared with filtered 99mTc-sulfur colloid without the green dye, which averaged $71 \pm$ $41 \mathrm{~nm}(n=41)$. Measurements of unfiltered 99mTc-sulfur colloid were recorded at $253 \pm 192 \mathrm{~nm}(n=21)$ for additional comparisons. Conclusion: The chemical properties and particle size of filtered $99 \mathrm{mT}$ c-sulfur colloid were not affected by the addition of the green dye; thus, combination of filtered ${ }^{99 m T c-s u l f u r ~ c o l l o i d ~}$ and green dye in the same syringe for administration is suitable.

Key Words: filtered 99mTc-sulfur colloid; indocyanine green dye; sentinel node lymphoscintigraphy; gallbladder and biliary tract cancers
\end{abstract}

J Nucl Med Technol 2012; 40:194-197

DOI: 10.2967/jnmt.111.097584

$\mathbf{E}$ ach year in the United States, there are approximately 9,250 new cases of gallbladder cancer and between 2,000 and 3,000 new cases of bile duct cancer $(1,2)$. These 2 types

Received Aug. 27, 2011; revision accepted Jan. 24, 2012.

For correspondence or reprints contact: Joseph C. Hung, Department of

Radiology, Mayo Clinic, 200 First St. SW, Rochester, MN 55905-0001.

E-mail: jhung@mayo.edu

Published online Jun. 7, 2012.

COPYRIGHT (C) 2012 by the Society of Nuclear Medicine and Molecular Imaging, Inc. of cancer make up all biliary tract cancers. These patients can be cured only by resection of the tumor, provided the cancer has not metastasized (3). Once the cancer has metastasized to regional lymph nodes, the 2-y survival rate is $4 \%$ (3). In order to determine whether the cancer has metastasized to the lymph nodes a lymph node biopsy is performed. In some cases, this can be complicated because lymphatic drainage around the biliary tree is complex and can be altered greatly by the presence of a tumor. There are several node locations in the axial body of the biliary tree, making it difficult to predict whether the lymphatic vessels are traveling to the inguinal nodes, sternal nodes, stomach nodes, axillary nodes, or another location. Therefore, the use of lymphoscintigraphy to identify sentinel lymph nodes would be beneficial.

Currently, lymphoscintigraphy is used in cases of breast cancer and melanoma to locate sentinel lymph nodes (4). In this procedure, a radioactive material called filtered ${ }^{99 \mathrm{~m} T c-}$ sulfur colloid is injected subcutaneously around the area of the malignancy, where it enters into the lymphatic system and is trapped in the lymph node by phagocytic activity (4). In addition to the radioactive colloid, isosulfan blue dye may also be injected for lymph node localization (5). In surgery, the combination of these 2 materials helps surgeons more accurately determine which lymph nodes to remove for biopsy. Because of this procedure, lymph node resection is much less invasive than in the past.

Lymphoscintigraphy and the dye method for localization have not been widely applied to gallbladder and biliary tract cancers. The current study explored the process of combining filtered ${ }^{99 \mathrm{~m}} \mathrm{Tc}$-sulfur colloid with indocyanine green for injection, U.S. Pharmacopeia (USP) (Akorn, Inc.), for the purpose of locating sentinel nodes. More specifically, the compatibility and stability of the physical and chemical components of the filtered ${ }^{99 \mathrm{~m}} \mathrm{Tc}$-sulfur colloid were examined to ensure that there are no changes in the properties of filtered ${ }^{99 \mathrm{~m}} \mathrm{Tc}$-sulfur colloid due to the addition of the green dye. The properties that we tested were radiochemical purity $(\mathrm{RCP}), \mathrm{pH}$, and particle size. Indocyanine green dye was chosen rather than isosulfan blue dye because this green dye has been previously used for locating sentinel nodes in gastric cancers and was found to cause fewer allergic reactions than the blue dye (6). 


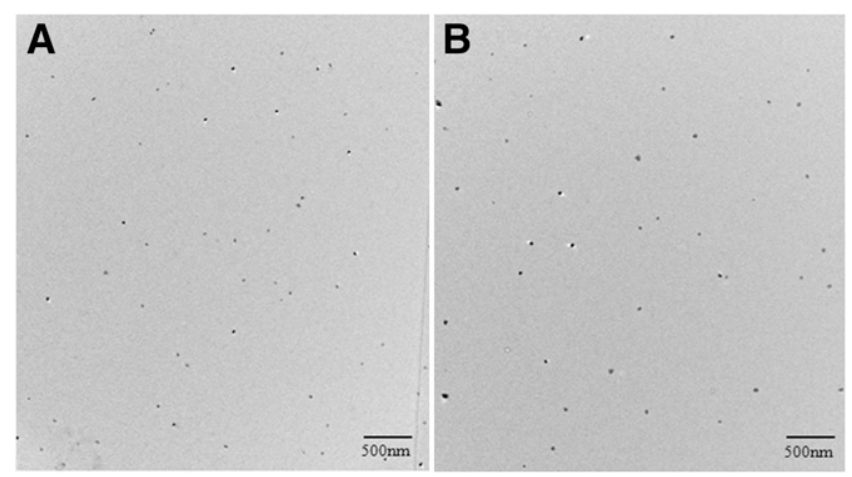

FIGURE 1. (A) Filtered $99 \mathrm{mT}$ T-sulfur colloid particles when mixed with green dye at $0 \mathrm{~h}$ after preparation. (B) Filtered 99mTc-sulfur colloid particles when mixed with green dye at $2 \mathrm{~h}$ after preparation.

\section{MATERIALS AND METHODS}

\section{Mixture of Filtered ${ }^{99 m}$ Tc-Sulfur Colloid and Green Dye}

${ }^{99 \mathrm{~m}} \mathrm{Tc}$-sulfur colloid (cold kits obtained from Pharmalucence) was prepared according to the package insert, and the final preparation was passed through a $0.2-\mu \mathrm{m}(200-\mathrm{nm})$ filter (7). The final compounded product was visually examined for particulate matter. Tricarbocyanine (IC-Green; Akorn, Inc.), a sterile, lyophilized green powder for the preparation of indocyanine green for injection, USP, was also reconstituted according to the direction of the package insert (8). To determine the best amount of green dye to have in each syringe, 4 samples containing different amounts were created. The syringes contained $0.1,0.15,0.2$, or $0.25 \mathrm{~mL}$ of green dye and were diluted to $0.5 \mathrm{~mL}$ with normal saline. It was then determined that the sample containing $0.25 \mathrm{~mL}$ of green dye was ideal because it was the darkest.

Therefore, in a sterile syringe $0.25 \mathrm{~mL}$ of filtered ${ }^{99 \mathrm{~m}} \mathrm{Tc}$-sulfur colloid containing $14.8 \mathrm{MBq}(400 \mu \mathrm{Ci})$ of activity was drawn. The filtered ${ }^{99 \mathrm{~m}} \mathrm{Tc}$-sulfur colloid was then combined with $0.25 \mathrm{~mL}$ of $1.25-\mathrm{mg}$ green dye in the same syringe. The result was a 1:1 mixture with a total volume of $0.5 \mathrm{~mL}$. Three syringes were created in this manner for each trial with the exception of trial 2. During trial 2, only 2 syringes were used because 1 became contaminated.

\section{RCP Testing}

RCP was tested immediately after preparation as well as 1 and $2 \mathrm{~h}$ after preparation. The method used to measure RCP was in accordance with the USP monograph for ${ }^{99 \mathrm{~m}} \mathrm{Tc}$-sulfur colloid injection and the Mayo Clinic Nuclear Pharmacy Procedure Manual
$(9,10)$. A small drop of the filtered ${ }^{99 \mathrm{~m}} \mathrm{Tc}$-sulfur colloid and green dye mixture was placed on one end of a Whatman 31ET strip of chromatography paper (10), which was then placed in a glass test tube containing a solvent, $85 \%$ methanol (9). Care was taken to ensure the drop placed on the chromatography paper was above the level of the solvent. A rubber cap was placed on the top of the tube to maintain equilibrium. Once the solvent had been given sufficient time to migrate the length of the chromatography paper, the paper was removed and cut in half (10). Each end of the paper was measured separately in a dose calibrator. From this, the percentage RCP was calculated and the results were recorded; the RCP limit, according to the USP, is $92 \%$ bound (9).

\section{Evaluation of $\mathrm{pH}$}

The $\mathrm{pH}$ of the mixture was measured immediately after preparation, as well as 1 and $2 \mathrm{~h}$ after preparation. A small sample was taken from each syringe containing the mixture and placed into a small plastic cup. The $\mathrm{pH}$ was measured by gently swirling the $\mathrm{pH}$ probe in the mixture and recording the results displayed on the $\mathrm{pH}$ meter (model 617P; Jenco Instruments). The $\mathrm{pH}$ needed to fall within the range of $4.5-7.5$ to be in accordance with the USP (9).

\section{Particle Size Assessment}

Particle size was evaluated with an electron microscope (Technai 12 TEM; FEI Co.). Particle size was evaluated immediately after preparation and $2 \mathrm{~h}$ after preparation. A large drop of the mixture was mounted on a plastic-coated copper grid and allowed to dry. Distilled water was then placed on the grid and removed several times using chromatography paper to remove water-soluble salts, leaving the filtered ${ }^{99 \mathrm{~m} T c}$-sulfur colloid particles on the grid. Images were then captured at different magnifications. Copies of these images were printed, the micron bar located on the image was used to determine the size of the particles, and the results were recorded (Fig. 1). In addition to testing the particle size of the filtered ${ }^{99 \mathrm{~m}} \mathrm{Tc}$-sulfur colloid when combined with green dye, we tested the particle size of ${ }^{99 \mathrm{~m}} \mathrm{Tc}$-sulfur colloid and filtered ${ }^{99 \mathrm{~m}} \mathrm{Tc}$-sulfur colloid without green dye in the same manner for comparison (Fig. 2).

\section{RESULTS \\ RCP Testing}

The average RCP was $97.6 \% \pm 2.0 \%(n=51)$, with a range of $92.3 \%-99.7 \%$ (Table 1). Three samples were tested in 5 trials immediately after preparation and 1 and $2 \mathrm{~h}$ after preparation, and 2 samples were tested in a single trial immediately after preparation and 1 and $2 \mathrm{~h}$ after prep-

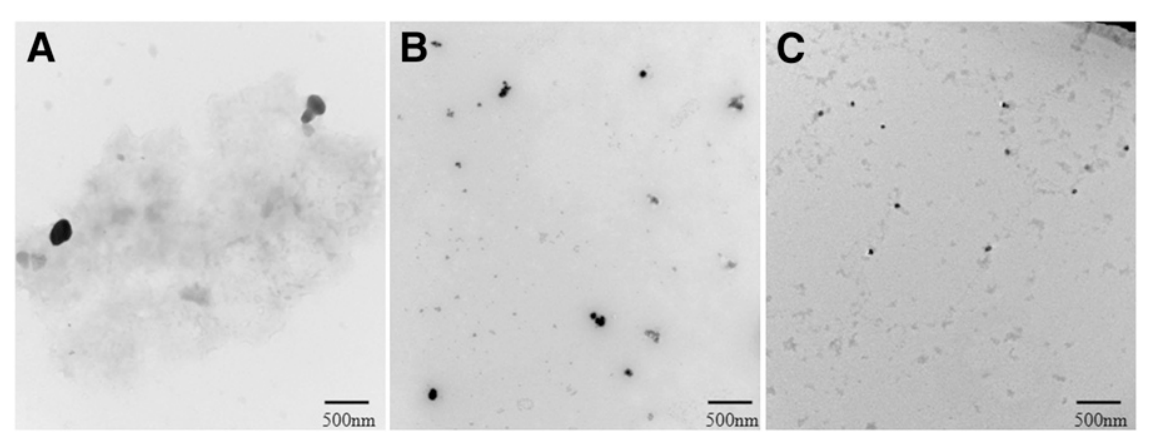

FIGURE 2. (A) ${ }^{99 m}$ Tc-sulfur colloid particles without green dye. (B) Filtered $99 \mathrm{mTc}$ sulfur colloid particles without green dye. (C) Filtered ${ }^{99 \mathrm{~m} T c}$-sulfur colloid with green dye. 
TABLE 1

Evaluation of RCP

\begin{tabular}{lcccc}
\hline Trial & $n$ & $\begin{array}{c}\text { Average RCP } \\
(\%) \text { at } 0 \mathrm{~h}\end{array}$ & $\begin{array}{c}\text { Average RCP } \\
(\%) \text { at } 1 \mathrm{~h}\end{array}$ & $\begin{array}{c}\text { Average RCP } \\
(\%) \text { at } 2 \mathrm{~h}\end{array}$ \\
\hline 1 & 3 & $96.1 \pm 0.1$ & $97.5 \pm 0.1$ & $99.0 \pm 0.1$ \\
2 & 2 & $98.9 \pm 0.0$ & $95.4 \pm 0.0$ & $94.1 \pm 0.0$ \\
3 & 3 & $99.6 \pm 0.1$ & $97.9 \pm 0.1$ & $98.1 \pm 0.1$ \\
4 & 3 & $96.5 \pm 0.0$ & $99.1 \pm 0.0$ & $98.5 \pm 0.0$ \\
5 & 3 & $98.9 \pm 0.0$ & $98.7 \pm 0.0$ & $97.5 \pm 0.0$ \\
6 & 3 & $94.5 \pm 0.1$ & $96.6 \pm 0.1$ & $98.1 \pm 0.1$
\end{tabular}

aration, for a total of 51 measurements. All samples passed the USP RCP limit of $92 \%$ bound (9).

\section{Evaluation of $\mathrm{pH}$}

The average $\mathrm{pH}$ was $5.56 \pm 0.26(n=51)$, and the range was 4.99 to 5.91 (Table 2). All samples fell within the USP limits for $\mathrm{pH}$ range, 4.5-7.5 (9).

\section{Particle Size Assessment}

The average particle size for filtered ${ }^{99 \mathrm{~m}} \mathrm{Tc}$-sulfur colloid combined with green dye was $53 \pm 30 \mathrm{~nm}(n=365)$ at $0 \mathrm{~h}$ after preparation and $60 \pm 35 \mathrm{~nm}(n=303)$ at $2 \mathrm{~h}$ after preparation. Analysis showed a statistically significant difference ( $P=0.00878$ when using a paired $t$ test and $P=$ 0.0341 when using an unpaired $t$ test) between the 2 time points. Filtered ${ }^{99 \mathrm{~m}} \mathrm{Tc}$-sulfur colloid without green dye had an average particle size of $71 \pm 41 \mathrm{~nm}(n=41)$ Measurements of unfiltered ${ }^{99 \mathrm{~m}} \mathrm{Tc}$-sulfur colloid were recorded at $253 \pm 192 \mathrm{~nm}(n=21)$ (Table 3).

\section{DISCUSSION}

All values obtained throughout the experiment were compared with the USP monograph for ${ }^{99 \mathrm{~m}} \mathrm{Tc}$-sulfur colloid injection to ensure the results were in compliance with USP standards (9). No samples fell below the $92 \%$ limit for RCP (Table 1). Over the $2 \mathrm{~h}$ that RCP was recorded, there was no significant change in percentage bound (Table 1). Therefore, the addition of the green dye to the filtered ${ }^{99 \mathrm{~m}} \mathrm{Tc}$-sulfur colloid did not have a detrimental effect on RCP value. Also, no tested samples of the mixture fell outside the acceptable range for $\mathrm{pH}$ set by the USP, and there was no significant change in $\mathrm{pH}$ over $2 \mathrm{~h}$ (Table 2). Both properties were tested until the 2-h mark because of our in-house guidelines for filtered ${ }^{99 \mathrm{~m}} \mathrm{Tc}$-sulfur colloid that only allow injection of this material for up to $2 \mathrm{~h}$ after formulation (10).

There is no USP guideline for the particle size of filtered 99mTc-sulfur colloid; however, since the reconstituted ${ }^{99 \mathrm{~m}} \mathrm{Tc}$-sulfur colloid was passed though a $0.2-\mu \mathrm{m}$ (200-nm) filter, all sulfur colloid particles needed to be smaller than $200 \mathrm{~nm}$. As per the experimental outcome (Table 3), the average particle size of filtered ${ }^{99 \mathrm{~m}} \mathrm{Tc}$-sulfur colloid when combined with green dye was well below $200 \mathrm{~nm}$. Of the particles measured, none were greater than $200 \mathrm{~nm}$ (Table $3)$. Favored particle size for lymphoscintigraphy is between
5 and $50 \mathrm{~nm}(11)$. If the particles are less than $5 \mathrm{~nm}$, they are cleared from the injection site through the blood as well as through the lymphatic system (11). If the particles are too large they will migrate through the lymphatic system poorly and therefore cause delayed lymphatic drainage (11). The average size of the particles in this experiment was $53 \pm 30 \mathrm{~nm}$ immediately after formulation and $60 \pm$ $35 \mathrm{~nm} 2 \mathrm{~h}$ after formulation (Table 3). These results indicate that although on the high side of the ideal size range, they are still acceptable.

Even though our statistical analyses showed significant differences in particle sizes at 0 and $2 \mathrm{~h}$ after preparation, the difference had little impact on the actual use of this radiopharmaceutical in this clinical application. The particles did not clump or have any other physical changes that could be seen with an electron microscope. Therefore, the addition of the green dye did not affect the physical state of the filtered ${ }^{99 \mathrm{~m}} \mathrm{Tc}$-sulfur colloid particles.

In Japan, a small study involving 12 patients used filtered 99mTc-sulfur colloid to map lymphatic drainage near the gallbladder and biliary tract and locate sentinel lymph nodes (12). However, this technique could be improved by adding the use of a dye. If a radiotracer is used as the only method of localization, no visualization is possible and shine-through from the injection site can make sentinel node detection difficult $(6,11)$. Because these tumors are located more internally than a breast tumor or melanoma lesion, a subcutaneous injection technique is not applicable. Therefore, the injections would need to take place during surgery around the area of the tumor. It would be beneficial to combine the radioactive material with the dye because each material, when used on its own, has limitations. The green dye transports rapidly through the lymphatic system once it is injected and causes too many lymph nodes to show up (11). Also, loss of visibility occurs in dense fat tissue (6).

A study in Korea found that using both methods of localization simultaneously was beneficial in cases of gastric cancer (11). When dye alone was used, they were able to detect sentinel nodes in $73.5 \%$ of patients and the sensitivity was $72.2 \%$; when radiotracer alone was used, they were able to detect sentinel nodes in $80.9 \%$ of patients and the sensitivity was $83.3 \%(11)$. When the 2 methods were used together, sentinel nodes were detected in $91.2 \%$ of patients and the sensitivity was $100 \%$ (11).

TABLE 2

Evaluation of $\mathrm{pH}$

\begin{tabular}{lcccc}
\hline Trial & $n$ & $\begin{array}{c}\text { Average } \\
\mathrm{pH} \text { at } \mathrm{h}\end{array}$ & $\begin{array}{c}\text { Average } \\
\mathrm{pH} \text { at } 1 \mathrm{~h}\end{array}$ & $\begin{array}{c}\text { Average } \\
\mathrm{pH} \text { at } 2 \mathrm{~h}\end{array}$ \\
\hline 1 & 3 & $5.07 \pm 3.43$ & $5.18 \pm 2.44$ & $5.18 \pm 0.13$ \\
2 & 2 & $5.61 \pm 0.02$ & $5.78 \pm 2.68$ & $5.85 \pm 0.88$ \\
3 & 3 & $5.58 \pm 0.07$ & $5.77 \pm 0.34$ & $5.47 \pm 0.94$ \\
4 & 3 & $5.30 \pm 2.09$ & $5.38 \pm 0.09$ & $5.59 \pm 0.16$ \\
5 & 3 & $5.58 \pm 0.44$ & $5.87 \pm 0.60$ & $5.77 \pm 2.42$ \\
6 & 3 & $5.62 \pm 1.98$ & $5.84 \pm 1.93$ & $5.88 \pm 1.11$ \\
\hline
\end{tabular}


TABLE 3

Evaluation of Particle Size

\begin{tabular}{|c|c|c|c|c|}
\hline Sample & $n$ & $\begin{array}{c}\text { Average particle } \\
\text { size }(n m)\end{array}$ & $\begin{array}{c}\text { Minimum particle } \\
\text { size }(\mathrm{nm})\end{array}$ & $\begin{array}{c}\text { Maximum particle } \\
\text { size }(\mathrm{nm})\end{array}$ \\
\hline Unfiltered ${ }^{99 m}$ Tc-sulfur colloid & 21 & $253 \pm 192$ & 31 & 857 \\
\hline Filtered 99mTc-sulfur colloid & 41 & $71 \pm 41$ & 19 & 167 \\
\hline Mixture of filtered ${ }^{99 \mathrm{~m} T c}$-sulfur colloid and green dye at $0 \mathrm{~h}$ & 365 & $53 \pm 30$ & 9 & 156 \\
\hline Mixture of filtered ${ }^{99 m}$ Tc-sulfur colloid and green dye at $2 \mathrm{~h}$ & 303 & $60 \pm 35$ & 12 & 193 \\
\hline
\end{tabular}

\section{CONCLUSION}

The chemical properties and particle size of filtered ${ }^{99 \mathrm{~m}} \mathrm{Tc}$-sulfur colloid were not affected by the addition of the green dye; thus, combination of filtered ${ }^{99 \mathrm{~m}} \mathrm{Tc}$-sulfur colloid and green dye in the same syringe for administration is suitable. In addition, the overall experiment was considered to be simple and highly reproducible. In the future, this mixture can be used as a single injection, and sentinel nodes can possibly be better identified in patients with gallbladder and biliary tract tumors.

\section{ACKNOWLEDGMENTS}

We thank Jon E. Charlsworth, Electron Microscopy RES CORE Facility, Department of Biochemistry and Molecular Biology, Mayo Clinic, for his procedural assistance in the determination of particle size. In addition, we thank Florencia G. Que, Division of Gastroenterological and General Surgery, Department of Surgery, Mayo Clinic; Brian P. Mullan, Division of Nuclear Medicine, Department of Radiology, Mayo Clinic; and Thomas Herold, CNMT, Division of Nuclear Medicine, Department of Radiology, Mayo Clinic, for their methodologic assistance in preparing filtered ${ }^{99 \mathrm{~m}} \mathrm{Tc}$-sulfur colloid and green dye mixture. Lastly, we thank Jodi Olson, Media Support Services, Mayo Clinic, for her assistance with photography for the figures in this paper. This paper was presented at the 58th annual meeting of the Society of Nuclear Medicine, San Antonio, Texas, on
June 6, 2011. No potential conflict of interest relevant to this article was reported.

\section{REFERENCES}

1. What are the key statistics about gallbladder cancer? American Cancer Society Web site. Available at: www.cancer.org/Cancer/GallbladderCancer/DetailedGuide/ gallbladder-key-statistics. Accessed May 8, 2012.

2. What are the key statistics about bile duct cancer? American Cancer Society Web site. Available at: www.cancer.org/Cancer/BileDuctCancer/DetailedGuide/bileduct-cancer-key-statistics. Accessed May 8, 2012.

3. Gupta S, Shukla V. Gallbladder cancer etiopathology and treatment. Health Administrator. 2005;17:134-142.

4. Lymphoscintigraphy. RadiologyInfo.org Web site. Available at: www.radiologyinfo. org/en/info.cfm?pg=lympho. Accessed May 8, 2012.

5. Lymphazurin ${ }^{\mathrm{TM}}$ (isosulfan blue) injection [package insert]. Norwalk, CT: United States Surgical, Tyco Healthcare; 2005.

6. Miyashiro I, Kishi K, Yano M. Laparoscopic detection of sentinel node in gastric cancer surgery by indocyanine green fluorescence imaging. Surg Endosc. 2011; 25:1672-1676.

7. Kit for preparation of technetium Tc $99 \mathrm{~m}$ sulfur colloid injection [package insert]. Bedford, MA: Pharmalucence; 2008.

8. IC-GREEN ${ }^{\top M}$ (indocyanine green for injection, USP) [package insert]. Buffalo Grove, IL: Akorn Incorporated; 2008.

9. Technetium Tc 99m sulfur colloid injection. U.S. Pharmacopeia Web site. Available only to paid subscribers at: www.pharmacopeia.cn/v29240/usp29nf24s0_m80790. html. Accessed December 22, 2010.

10. Formulation of product: radiopharmaceutical Tc-99m filtered sulfur colloid $0.2 \mu \mathrm{m}$. In: Mayo Clinic Nuclear Medicine Procedure Manual. Rochester, MN: Mayo Clinic; 2006:1-2.

11. Park J, Kim H, Park Y. Simultaneous indocyanine green and ${ }^{99 \mathrm{~m}} \mathrm{Tc}$-antinomy sulfur colloid-guided laparoscopic sentinel basin dissection for gastric cancer. Ann Surg Oncol. 2011;18:160-165.

12. Toyoda T, Yoshida M, Endo M. Studies on hepatobiliary lymph flow with radioactive colloid for lymph node metastasis resection of carcinoma of the bifurcation of hepatic duct. Gastroenterol Jpn. 1986;21:35-43. 